\title{
Thermo-mechanical Treatment of 0.4C-0.6Mn-2Si Steel with Various Soaking and Annealing Hold Temperatures
}

Ludmila Kučerová, Martin Bystrianský, Štěpán Jeníček

Regional Technological Institute, University of West Bohemia in Pilsen, Univerzitní 8, 30614 Plzeň. Czech Republic. Email: skal@rti.zcu.cz,mbyst@rti.zcu.cz, jeniceks@rti.zcu.cz

\begin{abstract}
Middle carbon low alloyed steel $0.4 \mathrm{C}-0.6 \mathrm{Mn}-2 \mathrm{Si}$ was subjected to thermo-mechanical treatment typical for TRIP (transformation induced plasticity steels). The processing consisted from soaking at the temperatures of 850-1000 ${ }^{\circ} \mathrm{C}$ and cooling at $30{ }^{\circ} \mathrm{C} / \mathrm{s}$ to various annealing holds in bainite transformation temperature interval of $350-500{ }^{\circ} \mathrm{C}$. During the cooling from the soaking temperature, two compressive deformations were carried out, the second one always at $720{ }^{\circ} \mathrm{C}$. Resulting microstructures were analysed using light and scanning electron microscopy. X-ray diffraction phase analysis was carried out to establish volume fraction of retained austenite and mechanical properties were measured by tensile test. Tensile strengths in the region of 847-963 MPa were obtained and very good total elongations of $30-40 \%$ were achieved at the same time. Multiphase microstructures were obtained with various amounts of ferrite, bainite, retained austenite and pearlite.
\end{abstract}

Keywords: Middle carbon steel, Thermo-mechanical treatment, Retained austenite, TRIP steel

\section{Introduction}

Thermo-mechanical processing is a typical treatment used for preparation of complex multiphase microstructures which are able to display a TRIP (transformation induced plasticity) effect [1]. These microstructures usually consist of a mixture of ferrite, bainite and retained austenite and retained austenite is considered crucial for achievement of good mechanical properties [2-5]. The first generations of advanced TRIP steels possessed a matrix of polygonal ferrite with around $25 \%$ of bainite and $15 \%$ of retained austenite $[1,2]$. Lately, variations of bainite-based microstructures with smaller amounts of ferrite and still around $15 \%$ of retained austenite appeared. It was generally stated that TRIP steels could be based on a simple chemical concept of $0.2-0.4 \%$ of carbon, $1-2 \%$ of manganese and silicon [6-14]. However, most of the research has been always concentrated on low alloyed steels with lower carbon contents around $0.2 \% \mathrm{C}$ [1-8] and less attention has been paid to middle carbon steel [9-18]. Manganese is added to increase chemical stability of austenite against martensitic transformation during final cooling and thus increase the amount of retained austenite in the final microstructure. Even though silicon is a ferrite forming element, it is used in TRIP steels for the very same reason as manganese. Silicon does not dissolve in cementite and therefore postpones cementite formation during the processing, particularly during the annealing hold. Pearlitic microstructure is considered to be undesirable in TRIP steels, because it consumes carbon, which should be used for retained austenite stabilization instead $[1,3]$.

Thermo-mechanical processing of TRIP steel is relatively simple, consisting of soaking in either fully austenitic temperature interval or at various intercritical temperatures, deformation at the soaking temperature or during cooling to the annealing hold temperature [12-16]. Annealing hold is a typical feature of TRIP steel processing, offering possibility for remaining austenite carbon enrichment and creation of sufficient amount of bainite.
In this article, the steel with higher carbon content of $0.4 \% \mathrm{C}$ and little further alloying with $0.6 \%$ manganese and $2 \%$ of silicon.

\section{Experimental program}

\subsection{Material}

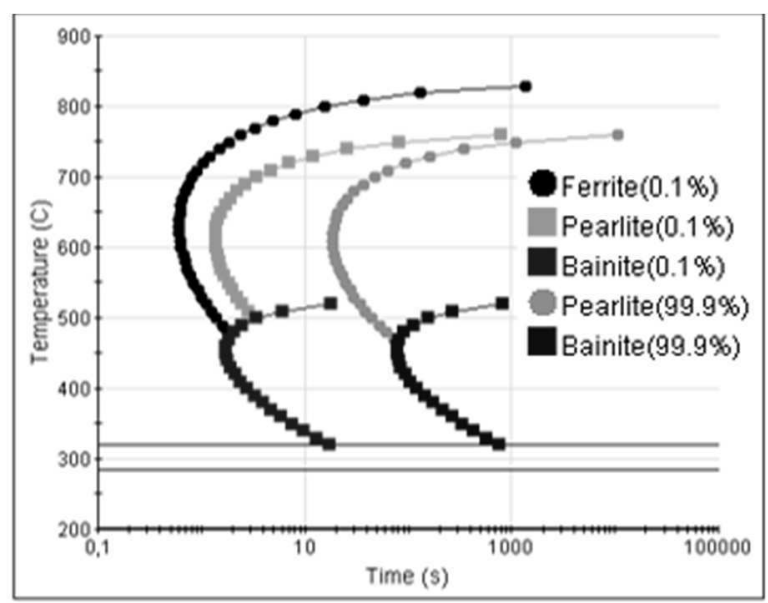

Fig. 1 TTT diagram calculated in JMatPro

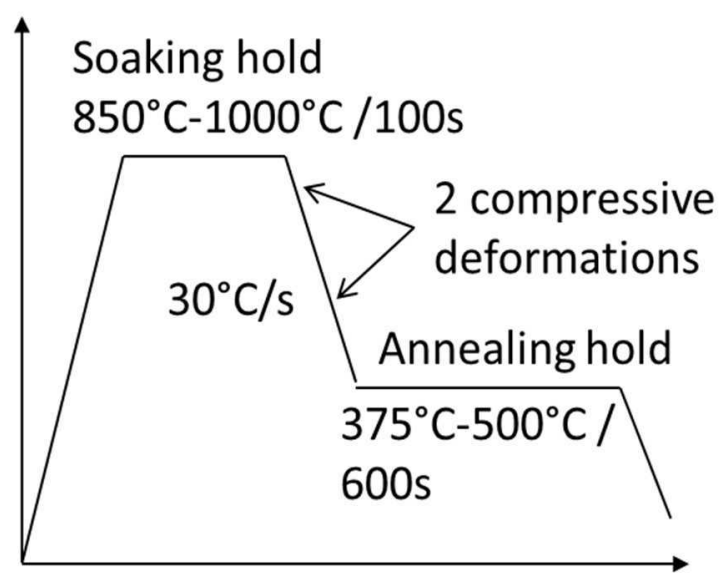

Fig. 2 Scheme of thermo-mechanical processing 
Middle carbon, low alloyed steel $0.4 \% \mathrm{C}-0.6 \% \mathrm{Mn}-$ $2 \% \mathrm{Si}$ (in weight percents) was used in this work. TTT (time temperature transformation) diagram of this steel was calculated by JMatPro software for a soaking temperature of $850^{\circ} \mathrm{C}$ (Fig. 1). Calculated bainite transformation temperatures were in the region of circa $325-510{ }^{\circ} \mathrm{C}$. Annealing hold temperatures of $375-500{ }^{\circ} \mathrm{C}$ were therefore chosen for proposed thermo-mechanical treatment (Fig. 2) to ensure sufficient bainite formation. Based on JMatPro calculations, three soaking temperatures of 850 ${ }^{\circ} \mathrm{C}, 900{ }^{\circ} \mathrm{C}$ and $1000{ }^{\circ} \mathrm{C}$ were chosen, which should lie in a one-phase, fully austenitic region.

\subsection{Thermo-mechanical processing}

Thermo-mechanical processing was carried out at MTS FlexTestSE electro-hydraulic simulator with maximum load of $50 \mathrm{kN}$ at actuator speeds of up to $3 \mathrm{~m} / \mathrm{s}$. This equipment enables precise control of heating and deformation parameters and high repeatability of desired processing conditions. The samples had cylindrical shape with diameter of $8 \mathrm{~mm}$ and active length of $16 \mathrm{~mm}$ which was optimized to ensure homogeneous distribution of heat and deformation across the active length of the sample.

Processing method typical for TRIP steels was chosen for experimental program (Fig. 2), consisting of a soaking hold in fully austenitic region, followed by two compressive deformations during the cooling to an annealing hold. The size of each deformation corresponded to $10 \%$ of an actual sample length and the last deformation was always applied at $720^{\circ} \mathrm{C}$. The cooling rate was kept 30 ${ }^{\circ} \mathrm{C} / \mathrm{s}$ for all the samples, the soaking temperatures varied from $850{ }^{\circ} \mathrm{C}$ to $1000{ }^{\circ} \mathrm{C}$. First of all, a set of annealing hold temperatures of $375-500{ }^{\circ} \mathrm{C}$ was tested for processing with the lowest soaking hold of $850{ }^{\circ} \mathrm{C}$. Annealing hold which yielded the best resulting properties was then used in thermo-mechanical treatments with increased soaking temperatures of $900{ }^{\circ} \mathrm{C}$ and $1000{ }^{\circ} \mathrm{C}$. Soaking hold was $100 \mathrm{~s}$ for all soaking temperatures and annealing hold of $600 \mathrm{~s}$ was used for all annealing temperatures.

\subsection{Microstructure analysis and testing}

Microstructures were characterized in the central part of processed samples by the means of BX61 Olympus light microscope and VEGA 3 and EVO 25 scanning electron microscopes (SEM) with a tungsten and a LaB6 cathode respectively. Volume fraction of the retained austenite was determined by an X-ray diffraction phase analysis using an AXS Bruker D8 Discover automatic powder diffractometer. Resulted volume fractions were rounded to the closest whole number. Carbon content in the retained austenite was calculated considering the effect of alloying elements according to [1]:

$$
\mathrm{a}=3,572+0,0012 \mathrm{Mn}-0,00157 \mathrm{Si}+0,0056 \mathrm{Al}+0,033 \mathrm{C}
$$

Where:

a ... lattice parameter of the retained austenite calculated from the three austenite peaks measured by X-ray diffraction phase analysis.

Mechanical properties were measured by tensile test of flat samples with an active length of $5 \mathrm{~mm}$ and a cross section of $1.2 \times 2 \mathrm{~mm}$. Two samples were tested for each processing method and average values are used in further text.

\section{Results and discussion}

\subsection{Effect of various annealing hold temperatures}

Thermo-mechanical processing with a soaking temperature of $850^{\circ} \mathrm{C}$ was carried out with the same thermal and deformation parameters except of an annealing hold temperature, which varied from $375^{\circ} \mathrm{C}$ to $500{ }^{\circ} \mathrm{C}$ to cover the calculated interval of bainitic transformation temperatures. The aim of these variations was to find the most convenient annealing temperature with regard to the final microstructure and mechanical properties.

Tab. 1 Parameters of thermo-mechanical treatment with two compressive deformations and cooling rate $30^{\circ} \mathrm{C} / \mathrm{s}$, resulting mechanical properties (yield strength Re, ultimate tensile strength Rm, total elongation A5mm), retained austenite volume fraction $(R A)$ and carbon content in retained austenite $\left(C_{R A}\right)$.

\begin{tabular}{|c|c|c|c|c|c|c|c|}
\hline $\begin{array}{l}\text { Soaking } \\
{\left[{ }^{\circ} \mathrm{C}\right] /[\mathrm{s}]}\end{array}$ & $\begin{array}{c}\text { Deformation tem- } \\
\text { peratures }\left[{ }^{\circ} \mathrm{C}\right]\end{array}$ & $\begin{array}{l}\text { Annealing } \\
\text { hold }\left[{ }^{\circ} \mathrm{C}\right]\end{array}$ & $\begin{array}{c}\mathrm{Re} \\
{[\mathrm{MPa}]}\end{array}$ & $\mathrm{Rm}[\mathrm{MPa}]$ & $\begin{array}{c}\mathrm{A}_{5 \mathrm{~mm}} \\
{[\%]}\end{array}$ & $\begin{array}{l}\mathrm{RA} \\
{[\%]}\end{array}$ & $\begin{array}{l}\mathrm{C}_{\mathrm{RA}} \\
{[\%]}\end{array}$ \\
\hline \multirow{5}{*}{$850 / 100$} & \multirow{5}{*}{850,720} & 375 & $523 \pm 3$ & $918 \pm 3$ & $38 \pm 2$ & 12 & 0.36190 \\
\hline & & 400 & $617 \pm 0$ & $857 \pm 2$ & $40 \pm 1$ & 13 & 0.36237 \\
\hline & & 425 & $603 \pm 4$ & $855 \pm 4$ & $41 \pm 1$ & 10 & 0.36231 \\
\hline & & 450 & $595 \pm 5$ & $858 \pm 0$ & $35 \pm 1$ & 5 & 0.36191 \\
\hline & & 500 & $627 \pm 7$ & $847 \pm 1$ & $30 \pm 0$ & - & - \\
\hline $900 / 100$ & 900,720 & 425 & $616 \pm 4$ & $884 \pm 2$ & $43 \pm 0$ & 10 & 0.36218 \\
\hline $1000 / 100$ & 900,720 & 425 & $638 \pm 2$ & $925 \pm 3$ & $42 \pm 1$ & 15 & 0.36216 \\
\hline
\end{tabular}


The lowest annealing temperature of $375^{\circ} \mathrm{C}$ resulted in a multiphase microstructure with rather fine ferritic matrix, coarser bainitic blocks and small areas of pearlite (Fig.3, Fig.4). Detailed images from SEM showed the presence of larger blocks of M-A constituent, which forms when austenitic grains are not stable enough to resist martensitic transformation during the cooling and sig- nificant part of these islands transforms to martensite. Despite the occurrence of pearlite, there was still $12 \%$ of the retained austenite in the final microstructure, which corresponds to the amount expected in steels displaying transformation induced plasticity effect. This could be also responsible for good mechanical properties of this microstructure, which reached an ultimate tensile strength of $918 \mathrm{MPa}$ with a total elongation of $38 \%$.
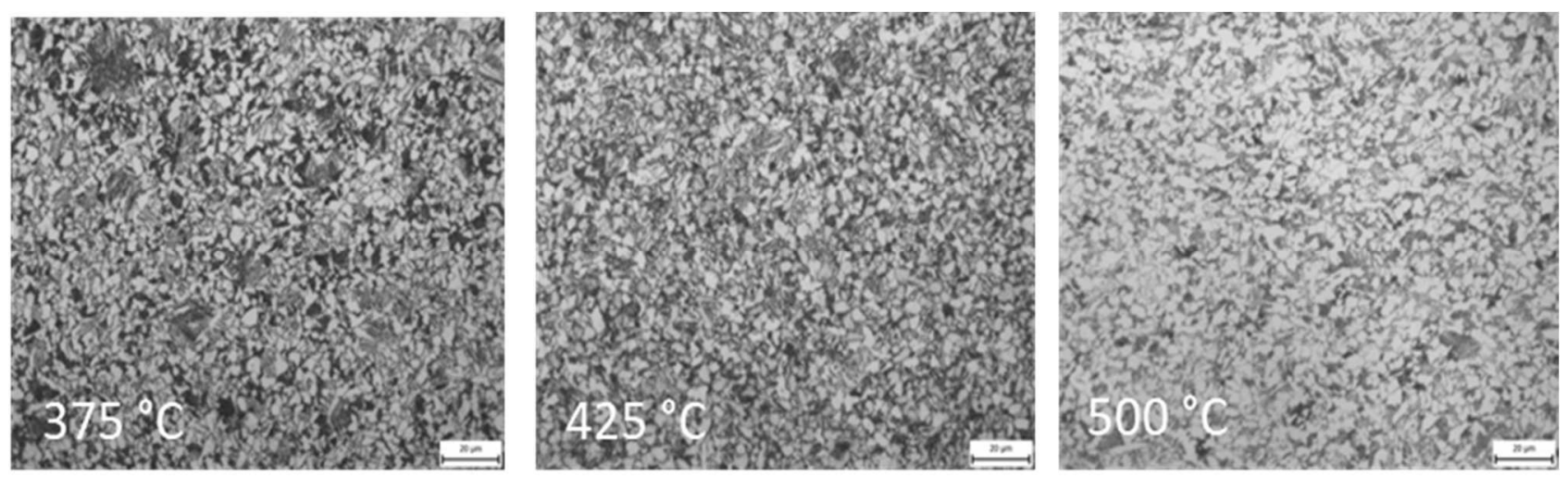

Fig. 3 Light micrographs of microstructures annealed at $375^{\circ} \mathrm{C}, 425^{\circ} \mathrm{C}$ and $500{ }^{\circ} \mathrm{C}$ (left to right)
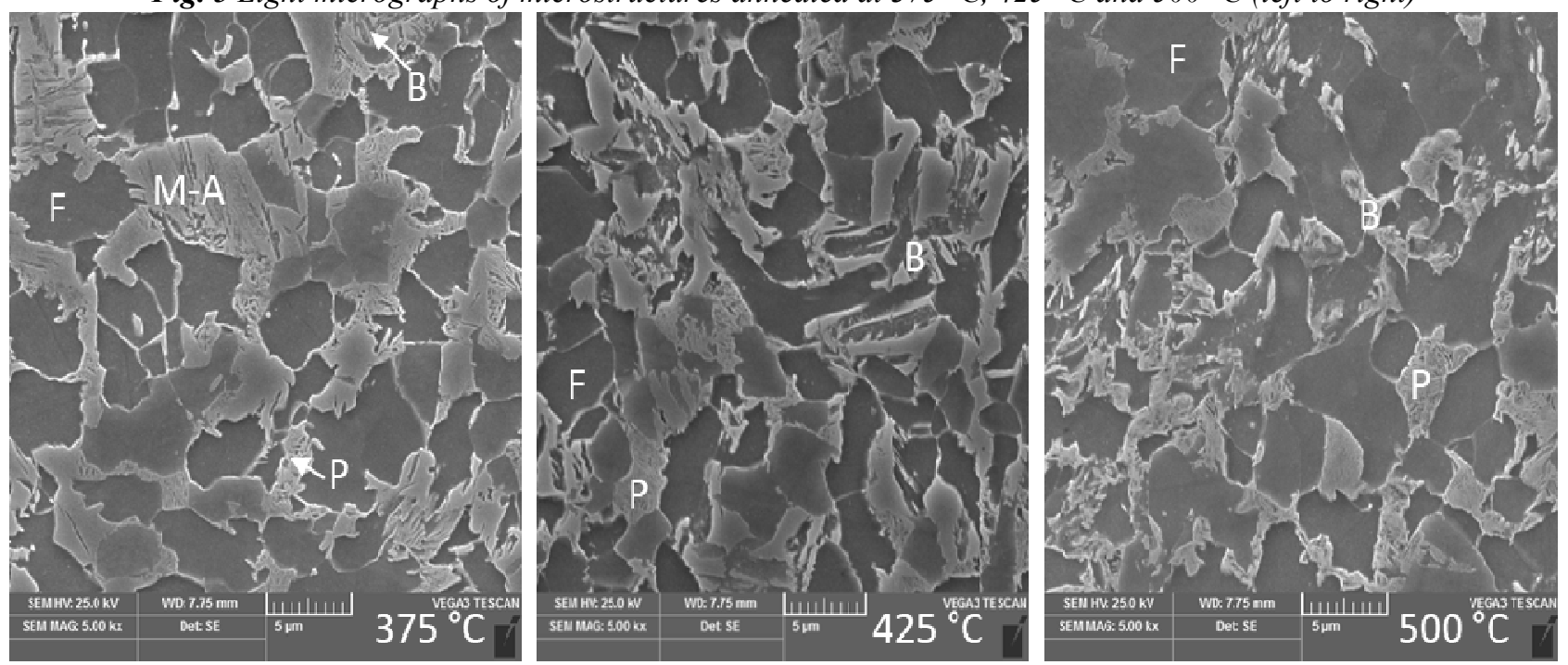

Fig. 4 Scanning electron micrographs of microstructures annealed at $375^{\circ} \mathrm{C}, 425^{\circ} \mathrm{C}$ and $500{ }^{\circ} \mathrm{C}$ (left to right, $\mathrm{F}-\mathrm{po}$ lygonal ferrite, $P$ - pearlite, $B$-bainite, $M$-A-austenitic islands partially transformed at martensite)

An increase of an annealing temperature to $400{ }^{\circ} \mathrm{C}$ resulted in lower amount of martensite in the final microstructure, which was reflected by lower tensile strength of $857 \mathrm{MPa}$ and slightly higher total elongation of $40 \%$. The volume fraction of the retained austenite reached $13 \%$, which was the highest value obtained in this work. It should be however noted, that $1 \%$ difference in retained austenite volume fraction is in this case insignificant. More important role for behaviour of the microstructure under mechanical load would play different carbon content in the retained austenite. Higher carbon content suggests higher stability of austenite obtained by the processing with annealing hold of $400{ }^{\circ} \mathrm{C}$.

Increase of the annealing temperature to $425{ }^{\circ} \mathrm{C}$ did not cause any change in mechanical properties and the microstructure was very similar to the one obtained by annealing at $400{ }^{\circ} \mathrm{C}$. Volume fraction of the retained austenite was smaller, reaching only $10 \%$, however its carbon content remained practically the same.

Further increase of the annealing hold to $450{ }^{\circ} \mathrm{C}$ resulted in a drop of total elongation to $35 \%$, while the strength still reached $858 \mathrm{MPa}$. This was caused by higher amount of carbides formed at higher annealing hold and accompanying drop of retained austenite volume to only $5 \%$.

Further deterioration of total elongation was observed for the processing with the highest annealing hold of 500 ${ }^{\circ} \mathrm{C}$. Ultimate tensile strength was still around $850 \mathrm{MPa}$ in this case, but the total elongation reached the lowest value of $30 \%$. The microstructure was basically a ferritic-pearlitic one and the amount of the retained austenite was below the detection limit of X-ray diffraction phase analy- 
sis. It can be seen from the comparison of this microstructure with the ones produced by processing with annealing holds of $400-425^{\circ} \mathrm{C}$ that stabilization of about ten percent of the retained austenite in a bainitic microstructure increased the total elongation of the steel by one third, while the change of an ultimate tensile strength was negligible.

The observed changes of the mechanical properties were not in agreement with the results obtained for the same steel after two step heat treatment without deformations [10]. The reason of the discrepancy probably lies in the large volumes of pearlite formed during the cooling from soaking temperature to the annealing temperature in the case of thermo-mechanical treatment, leaving lower amount of remaining austenite for further phase transformation and less carbon in remaining austenite.

The observed trends of mechanical properties also differ from the results published for low carbon TRIP steels, where increasing the temperature of the bainitic hold generally resulted in a decreasing strength and an increasing total elongation [19]. The plateau of tensile strength was also reported by Hausmann et al. [20] for $0.2 \mathrm{C}-2.6 \mathrm{Mn}$ $0.8 \mathrm{Si}-0.025 \mathrm{Nb}$ steel with tensile strengths in the region of 1200-1000 MPa, which also reached nearly constant strengths for hold temperatures in the interval of 425-450 ${ }^{\circ} \mathrm{C}$, followed by a quick drop after the treatment with a $475^{\circ} \mathrm{C}$ hold. The total elongation gradually increased from $12 \%$ to $18 \%$ with increasing hold temperature. Similar behaviour was observed for Al alloyed TRIP steel [4], where the highest total elongations were reached for annealing holds around $425{ }^{\circ} \mathrm{C}$, however these annealing temperatures produced relatively low tensile strengths which increased both at lower and higher annealing temperatures. It can be therefore seen, that even though temperatures around $425{ }^{\circ} \mathrm{C}$ are generally considered to be the best option for the annealing of TRIP steels, there is not a uniform trend of development of mechanical properties through the whole bainitic transformation temperatures interval.

\subsection{Effect of soaking temperatures}

Low soaking temperatures have the benefit of providing processing with lower energy consumption and thus higher cost efficiency. In the case of a soaking temperature of $850{ }^{\circ} \mathrm{C}$, the resulting microstructures were relatively fine and had homogeneous distribution of phases and fine ferrite matrix. On the other hand, the amount of bainite was low and pearlite was observed in all the microstructures. Increased soaking temperatures of $900{ }^{\circ} \mathrm{C}$ and $1000{ }^{\circ} \mathrm{C}$ resulted in microstructure coarsening, particularly of bainitic blocks (Fig. 5, Fig. 6). The microstructures were predominantly of a ferritic-bainitic type with fine areas of pearlite formed at the edges of bainitic blocks.
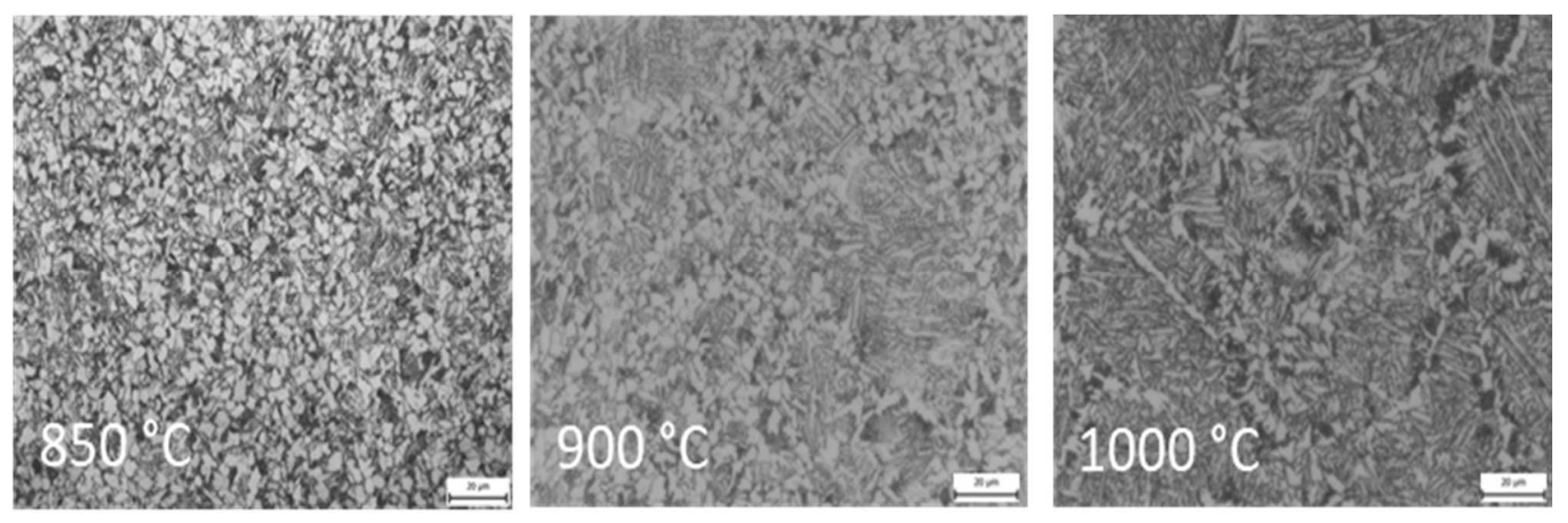

Fig. 5 Light micrographs of microstructures soaked at $850{ }^{\circ} \mathrm{C}, 900{ }^{\circ} \mathrm{C}$ and $1000^{\circ} \mathrm{C}$ (left to right)
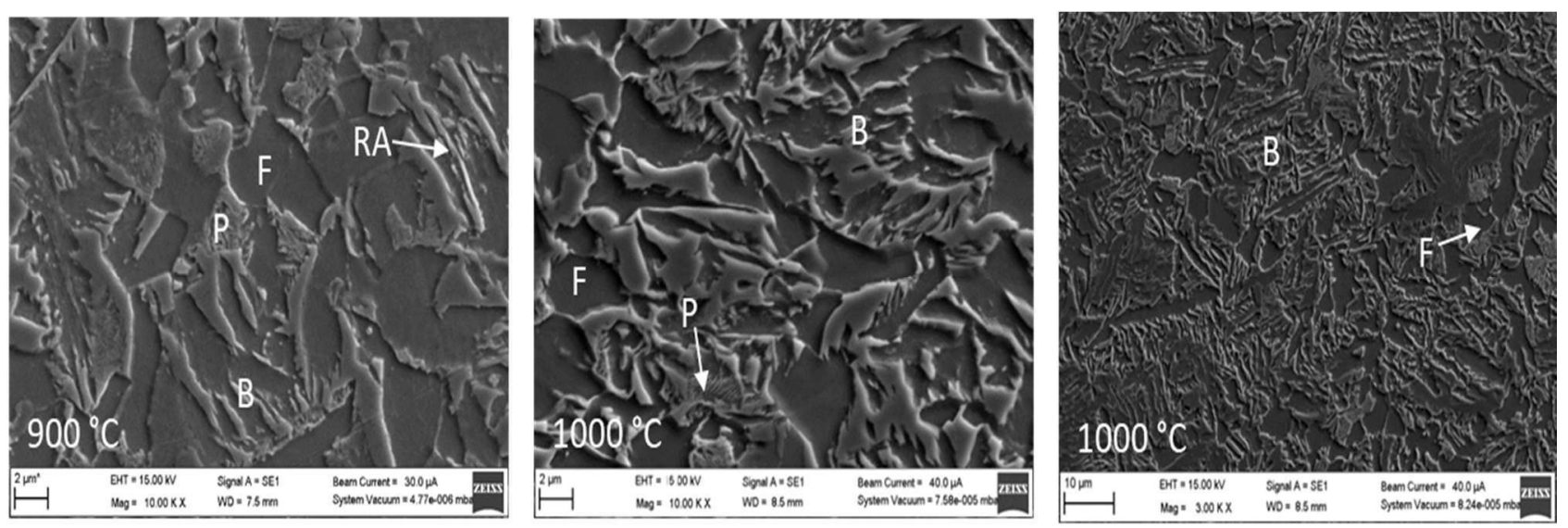

Fig. 6 Detailed scanning electron micrographs of microstructures soaked at $900{ }^{\circ} \mathrm{C}, 1000{ }^{\circ} \mathrm{C}$ and overview of microstructure soaked at $1000^{\circ} \mathrm{C}$ (left to right, $F$ - polygonal ferrite, $P$-pearlite, $B$-bainite, RA-retained austenite) 
Soaking temperature of $900{ }^{\circ} \mathrm{C}$ produced microstructure with higher strength of $884 \mathrm{MPa}$ and the best total elongation of $43 \%$, the amount of the retained austenite was the same as in the case of the same processing with soaking temperature of $850{ }^{\circ} \mathrm{C}$. Retained austenite formed laths in bainite and only few coarser islands of $\mathrm{M}$ A constituent were observed. Better mechanical properties should therefore be attributed mainly to the increased amount of bainite, rather than to the retained austenite alone. Smaller bainitic blocs were made of a granular bainite, while lath bainite prevailed in larger bainitic blocks.

The highest soaking temperature caused further coarsening of bainitic blocks which were separated by the chains of fine grains of proeutectoid ferrite. Larger areas of lath bainite were observed in this microstructure, with granular bainite at the edges or inside of small bainitic blocks. As in the previous microstructure, extremely fine pearlitic areas were found at the edges of bainitic blocks. This bainite-based microstructure with $15 \%$ of retained austenite possessed very interesting combination of high strength of $925 \mathrm{MPa}$ accompanied by high total elongation of $42 \%$.

In comparison with the behaviour of the same steel processed by two step heat treatment (without deformations) [8], the tensile strength in both cases increased with increasing soaking temperature. However, in the case of thermo-mechanical treatment, the total elongation very slightly increased with increasing temperature, while in the case of heat treatment alone, the highest total elongation of $47 \%$ was obtained for processing with soaking at $850{ }^{\circ} \mathrm{C}$ and it gradually dropped with increasing soaking temperature to $26 \%$ for $1000{ }^{\circ} \mathrm{C}$ soaking hold.

\section{Conclusions}

Thermo-mechanical treatment of 42SiMn steel with $0.4 \% \mathrm{C}$ was carried out with various soaking temperatures of $850-1000{ }^{\circ} \mathrm{C}$, cooling rate $30{ }^{\circ} \mathrm{C} / \mathrm{s}$ and several annealing hold temperatures in the range of $375-500{ }^{\circ} \mathrm{C}$. Two compressive deformations were applied during the cooling from a soaking to an annealing hold.

Cooling rate of $30{ }^{\circ} \mathrm{C} / \mathrm{s}$ was not quick enough for low soaking temperature of $850{ }^{\circ} \mathrm{C}$ to provide pearlite free microstructures, however retained austenite volume fractions were still around $10 \%$ for lower annealing hold temperatures. These microstructures consisted of the mixture of fine polygonal ferrite grains, bainitic areas, rather fine pearlite and for the lowest annealing hold of $375^{\circ} \mathrm{C}$ there were large islands of M-A constituent. The best combinations of tensile strengths around $850 \mathrm{MPa}$ and total elongations around $40 \%$ were achieved for annealing holds of $400-425{ }^{\circ} \mathrm{C}$.

When soaking temperature of used thermo-mechanical treatment with an annealing hold $425{ }^{\circ} \mathrm{C}$ was increased to $900{ }^{\circ} \mathrm{C}$ and $1000{ }^{\circ} \mathrm{C}$, even better mechanical properties were obtained. The microstructures were bainitic-ferritic with $10-15 \%$ of retained austenite and very fine pearlitic colonies. Tensile strength increased with increasing soaking hold to $925 \mathrm{MPa}$ with total elongations above $40 \%$.

\section{Acknowledgement}

The present contribution has been prepared within project LO1502 'Development of the Regional Technological Institute' under the auspices of the National Sustainability Programme I of the Ministry of Education, Youth and Sports of the Czech Republic.

\section{References}

[1] CHIANG, J., BOYD, J.D., PILKEY, A.K. (2015). Effect of microstructure on retained austenite stability and tensile behaviour in an aluminum-alloyed TRIP steel. In: Mater. Sci. Eng. A., Vol. 638, pp.132-142.

[2] JACQUES, P.J., FURNÉMONT, Q., LANI, F., PARDOEN, T., DELANNAY, F. (2007). Multiscale mechanics of TRIP-assisted multiphase steels: I. Characterization and mechanical testing. In: Acta Mater., Vol. 55, pp. 3681-3693.

[3] KUČEROVÁ, L., BYSTRIANSKÝ, M., JENÍČEK, Š., FRANCISCO, P. (2017). Effect of Deformation Conditions on Microstructure and Mechanical Properties of Low All-oyed Steel. In: Manufacturing Technology, Vol. 17, No 5, pp. 752-756.

[4] KUČEROVÁ, L., BYSTRIANSKÝ, M., KÁŇA, J. (2017). The effect of isothermal hold temperature on microstructure and mechanical properties of trip steel. In: Solid State Phenomena, pp. 253257.

[5] TIMOKHINA, I.B., HODGSON, P.D., PERELOMA, E.V. (2004). Effect of microstructure on the stability of retained austenite in transformation-induced-plasticity steels. In: Metall. Mater. Trans. A, Vol. 35, pp. 23312341.

[6] KUČEROVÁ, L., JIRKOVÁ, H., MAŠEK, B. (2017). The Effect of Alloying Elements on Microstructure of $0.2 \%$ C TRIP Steel. In: Mater. Sci. Forum, Vol. 891, pp. 209-213.

[7] KUČEROVÁ, L., JIRKOVÁ, H., MAŠEK, B. (2016). Influence of $\mathrm{Nb}$ Micro-alloying on TRIP Steels Treated by Continuous Cooling Process. In: Manufacturing Technology, Vol. 16, No. 1, pp. 145-149.

[8] KUČEROVÁ, L., JANDOVÁ, A., (2018). Effect of Thermo-Mechanical Treatment with Various Annealing Hold Conditions on Al Alloyed TRIP Steel. In: Manufacturing Technology, Vol. 18, No. 5, pp. 764-768.

[9] MATSUMURA, O., SAKUMA, Y., TAKECHI, H. (1987). Trip and its kinetic aspects in austempered 0.4C-1.5Si-0.8Mn steel. In: Scr. Metall., Vol. 21, pp. 1301-1306.

[10] KUČEROVÁ, L. (2017). The Effect of Two-Step Heat Treatment Parameters on Microstructure and 
Mechanical Properties of 42SiMn Steel. In: $\mathrm{Me}$ tals, 2017, Vol. 7, No. 12, pp. 1-14.

[11] GRAJCAR, A., KWASNY, W., ZALECKI, W. (2015). Microstructure-property relationships in TRIP aided medium- $\mathrm{C}$ bainitic steel with lamellar retained austenite. In: Mater. Sci. Technol., Vol. 31, pp. 781-794.

[12] KUČEROVÁ, L., JIRKOVÁ, H., JANDOVÁ, A. (2017). THERMO-MECHANICAL TREATMENT OF 42SICR AND 42MNSI STEELS. In: Acta Metallurgica Slovaca, Vol. 23, No. 3, pp. 244-250.

[13] BUSUKI, A., AERNOUDT, E. (1999). Effect of deformation in the intercritical area on the grain refinement of retained austenite of $0.4 \mathrm{C}$ trip steel. In: Scr. Mater., Vol. 40, pp.1003-1008.

[14] KOKOSZA, A., PACYNA, J. (2014). Formation of medium carbon TRIP steel microstructure during annealing in the intercritical temperature range. In: Arch. Metall. Mater., Vol. 59, pp.10171022.

[15] GRAJCAR, A., OPIELA M. (2008). Diagrams of supercooled austenite transformations of low-carbon and medium-carbon TRIP-steels. In: Arch. Mater. Sci. Eng., Vol. 32, pp. 13-16.
[16] JENÍČEK, Š., VOREL, I.., KÁŇA, J., OPATOVÁ, K. (2017). The Use of Material-Technological Modelling to Determine the Effect of Temperature and Amount of Deformation on Microstructure Evolution in a Closed-Die Forging Treated by Controlled Cooling. In: Manufacturing Technology, Vol. 17, No. 3, pp. 326-330.

[17] KUČEROVÁ, L., BYSTRIANSKÝ, M., JENÍČEK, Š. (2017). High ductility of bainitebased microstructure of middle carbon steel 42SiMn. In: IOP Conf. Ser. Mater. Sci. Eng., Vol. 179, pp. 1-7.

[18] BUBLÍKOVÁ, D., JENÍČEK, Š., KÁŇA, J., VOREL, I. (2018). Effects of Cooling Rate in an Innovative Heat Treatment Route for High-Strength Steels. In: Manufacturing Technology, Vol. 18, No.1, pp. 16-21.

[19] SUGimoto, K.I., MURATA, M., SONG, S.M. (2010). Formability of Al-Nb Bearing Ultra Highstrength TRIP-aided Sheet Steels with Bainitic Ferrite and/or Martensite Matrix. In: ISIJ Int., Vol. 50, pp. 162-168.

[20] HAUSMANN, K., KRIZAN, D., SPIRADEKHAHNB, K., PICHLERA, A., WERNERC, E. (2013). The influence of $\mathrm{Nb}$ on transformation behavior and mechanical properties of TRIP-assisted bainitic-ferritic sheet steels. In: Mater. Sci. Eng. $A$, Vol. 588, pp.142-150. 